\title{
Source, sea and sink-A holistic approach to understanding plastic pollution in the Southern Caribbean
}

\author{
Winnie Courtene-Jones ${ }^{\mathrm{a}, *}$, Taylor Maddalene ${ }^{\mathrm{b}}$, Molly K. James ${ }^{\mathrm{c}}$, Natalie S. Smith ${ }^{\mathrm{a}}$, Kathryn Youngblood ${ }^{\mathrm{b}}$, \\ Jenna R. Jambeck ${ }^{\mathrm{b}}$, Sally Earthrowl ${ }^{\mathrm{d}}$, Denise Delvalle-Borrero ${ }^{\mathrm{e}}$, Emily Penn ${ }^{\mathrm{d}}$, Richard C. Thompson ${ }^{\mathrm{a}}$ \\ a International Marine Litter Research Unit, School of Biological and Marine Sciences, University of Plymouth, Drake Circus, Plymouth, Devon PL4 8AA, UK \\ b College of Engineering, University of Georgia, Athens, GA 30602, USA \\ ' Plymouth Marine Laboratory, Prospect Place, Plymouth, PL1 3DH, UK \\ d eXXpedition, London, UK \\ e Laboratorio de Microplásticos, Centro de Investigaciones Hidráulicas e Hidrotécnicas (CIHH), Universidad Tecnológica de Panamá, Panamá, Panama
}

\section{H I G H L I G H T S}

- A holistic approach to plastic pollution which integrates land and marine research

- Local and distant sources contribute varied quantities and polymers of plastics.

- Paint fragments in surface water may arise from regional maritime industry/ tourism.

- PE, PP and PS in marine samples may arise from food packaging recorded in land transects.

- Results highlight the need for integrated, interdisciplinary collaborations on plastic pollution.

\section{A R T I C L E I N F O}

\section{Article history:}

Received 21 May 2021

Received in revised form 12 July 2021

Accepted 13 July 2021

Available online 17 July 2021

Editor: Kevin V Thomas

\section{Keywords:}

Microplastic

Waste management

Modelling

Litter

Plastic

Policy
G R A P H I C A L A B S T R A C T

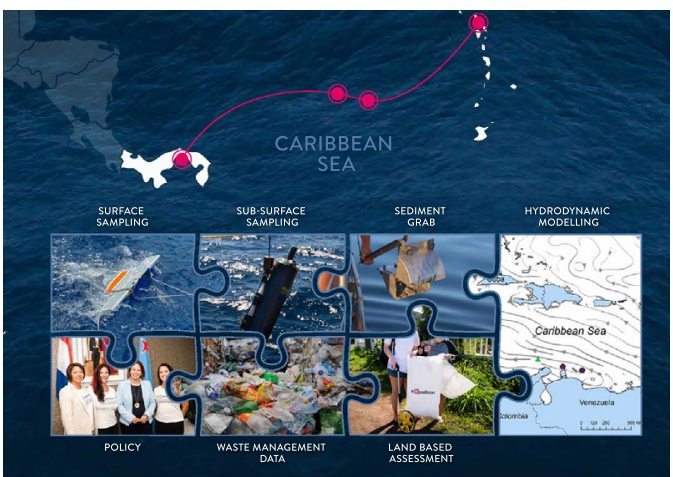

\begin{abstract}
A B S T R A C T
Marine plastics are considered to be a major threat to the sustainable use of marine and coastal resources of the Caribbean, on which the region relies heavily for tourism and fishing. To date, little work has quantified plastics within the Caribbean marine environment or examined their potential sources. This study aimed to address this by holistically integrating marine (surface water, subsurface water and sediment) and terrestrial sampling and Lagrangian particle tracking to examine the potential origins, flows and quantities of plastics within the Southern Caribbean. Terrestrial litter and the microplastics identified in marine samples may arise from the maritime and tourism industries, both of which are major contributors to the economies of the Caribbean region. The San Blas islands, Panama had the highest abundance of microplastics at a depth of $25 \mathrm{~m}$, and significantly greater quantities in surface water than recorded in the other countries. Modelling indicated the microplastics likely arose from mainland Panama, which has some of the highest levels of mismanaged waste. Antigua had among the lowest quantities of terrestrial and marine plastics, yet the greatest diversity of polymers. Modelling indicated the majority of the microplastics in Antiguan coastal surface were likely to have originated from the wider North Atlantic Ocean. Ocean currents influence the movements of plastics and thus the relative contributions arising from local and distant sources which become distributed within a country's territorial water. These transboundary movements can undermine local or national legislation aimed at reducing plastic pollution. While this study presents
\end{abstract}

\footnotetext{
* Corresponding author.

E-mail address: winnie.courtene-jones@plymouth.ac.uk (W. Courtene-Jones).
} 
a snapshot of plastic pollution, it contributes towards the void of knowledge regarding marine plastic pollution in the Caribbean Sea and highlights the need for international and interdisciplinary collaborative research and solutions to plastic pollution.

\section{Introduction}

There are substantial and increasing quantities of plastic pollution in the environment and the flux of plastics entering the oceans, primarily from land-based sources, is expected to continue to rise over the next decade (Geyer et al., 2017; Lebreton and Andrady, 2019). Owing to their durability, plastics can accumulate in the environment and their persistence has been reported over geological timescales (Ostle et al., 2019; Brandon et al., 2019; Courtene-Jones et al., 2020).

It is evidenced that plastics detrimentally impact marine life and ecological processes (Bucci et al., 2020; Galloway et al., 2017). In addition plastic pollution can adversely affect economy and society through impacts on food security (Barboza et al., 2018), human wellbeing (Beaumont et al., 2019; Wyles et al., 2016) and coastal economic activity (Rangel-Buitrago et al., 2018; Garces-Ordonez et al., 2020a; Ambrose et al., 2019), and as such plastics have been acknowledged as a pressing global issue (Sutherland et al., 2010; Rockström et al., 2009).

The tropics and the islands lying within this region are hotspots of biodiversity both above and below the water (Myers et al., 2000). These areas provide a wealth of ecosystem services, such as provision of food and generate income through tourism (Wilkinson and Salvat, 2012). Located within the tropics, the Caribbean region is a group of states and territories lying in or bordering the Caribbean Sea, and has a population of $\sim 44.4$ million (The World Bank, 2019). Only a small proportion (8.7\%) of the total region is dry land with an extensive marine territory. The lack of physical land space poses a pressing challenge for island nations around the world, in that they have a finite and often very limited amount of space for their primary form of waste management, which is typically sanitary landfill.

Few Caribbean countries have a comprehensive solid waste management framework and it is estimated that $54 \%$ of waste is disposed of in sanitary landfills, with much of the rest being dumped illegally or entering the marine environment (Diez et al., 2019; Riquelme et al., 2016; UNEP, 2018b; Phillips and Thorne, 2013). In 2018, it was estimated that the Caribbean and Latin America region comprised $11 \%$ of global waste production and less than $5 \%$ of that waste was being recycled. It has also been estimated that roughly $12 \%$ of the waste stream in the region is plastic (Kaza et al., 2018).

The accumulation of plastics in the marine environment is considered to be one of the most serious threats to sustainable use of the marine and coastal resources of the Caribbean (UNEP, 2014) and has ramifications on tourism on which the region relies heavily upon and which contributes $\sim 14 \%$ of the regions gross domestic product (World Travel and Tourism Council, 2020; Ambrose et al., 2019). It has also been suggested that island nations, such as those in the Caribbean will be disproportionately affected by increasing plastic pollution, due to their ocean-dependent economies and their still developing and vulnerable waste management infrastructure (Diez et al., 2019).

To date evidence of the spatial abundance of plastic within the marine environment of the Wider Caribbean Region is sparse (KutralamMuniasamy et al., 2020; Correa-Herrera et al., 2017; Botero et al., 2020; Kikaki et al., 2020). The distribution of plastic within ocean waters is influenced by their point of entry and the subsequent complex physical, chemical and biological interactions within the environment. Reports indicate the long-range movement of plastics between geographic regions (Ambrose et al., 2019; van Sebille et al., 2020), which may undermine local or national policies aimed at reducing plastic pollution.

The present study integrates marine plastic pollution research with modelling approaches, terrestrial litter assessments and regional policy; a holistic approach which has been largely lacking to date. The specific aims of this study were to spatially quantify the composition of (micro)plastics within different environmental compartments (the sea surface, subsurface water and subtidal sediments) in the Southern Caribbean region and consider the potential geographic origins of these particles. Terrestrial litter composition as well as Lagrangian particle tracking studies enabled further assessment of potential plastic pollution sources and the flow of plastic waste into the marine environment.

\section{Methods}

\subsection{Sample collection}

To study the distribution of microplastics within the Caribbean, sampling was performed from the sailing vessel TravelEdge as part of the 'Round the World' voyage organised by eXXpedition. Three transects involving sampling of surface water, subsurface water and subtidal sediment within the wider Caribbean region took place between 24th November and 20th December 2019 with scheduled stops along the route in Antigua, Bonaire, Aruba and the San Blas Islands before its final docking in Colón, Panama (Fig. 1 and SI Tables S1-S3).

\subsubsection{Surface water sampling}

Samples $(\mathrm{n}=19)$ were collected using an aluminium manta trawl (rectangular mouth, inner dimensions: $13.6 \mathrm{~cm}$ height $\times 64.4 \mathrm{~cm}$ wide) which had a $1.5 \mathrm{~m}$ long net with a detachable cod-end (30 $\times$ $10 \mathrm{~cm}$ ) both made from $335 \mu \mathrm{m}$ polyamide mesh. The manta trawl was towed along the sea-air interface using the spinnaker pole to position the towline outside of the wake of the vessel. For each 30 minute trawl the start and end GPS locations and times were recorded and were used to calculate the distance travelled (as in Jones-Williams et al., 2020; Law et al., 2014). The volume of water sampled through the trawl was subsequently estimated by multiplying the distance travelled by half of the net aperture $\left(0.04 \mathrm{~m}^{2}\right)$ : this assumes a laminar flow through the cod end of the net and that $50 \%$ of the net aperture was submerged as in other studies (Schonlau et al., 2020). The water volume was used to quantify the abundance of microplastics in surface waters.

Sampling only occurred in Beaufort Sea state $\leq 2$, and for all trawls environmental data including the sea state, wind speed and direction were also recorded. Once the manta trawl was recovered on board, the cod-end was removed. This was carefully inverted over three stacked sieves, of mesh sizes $4.75 \mathrm{~mm}, 1 \mathrm{~mm}$, and $0.335 \mathrm{~mm}$. A gentle flow of filtered seawater ( $50 \mu \mathrm{m}$, see Section 2.2) was used to facilitate the transfer of the contents of the cod-end into the sieves, and the cod-end was inspected thoroughly to ensure no microplastics remained on the net. Any natural debris, e.g. Sargassum sp. contained within the sieves were individually picked up with forceps and rinsed thoroughly with filtered seawater over the sieve and examined to ensure there were no microplastics adhered. Once cleaned, the natural debris was discarded. For the size fractions $4.75 \mathrm{~mm}$ and $1 \mathrm{~mm}$ from each trawl, all putative plastics were transferred into glass vials, separated by size, and for the $0.335 \mathrm{~mm}$ all material on the sieve was transferred. Samples were stored in the dark at ambient temperatures.

\subsubsection{Subsurface water sampling}

A 5 litre OSIL NISKIN bottle, made of dark grey PVC, was used to collect bulk subsurface water samples, with three replicates collected at each sampling location $(n=9)$. The bottle was deployed open, from the spinnaker pole using a blue polypropylene rope. It was deployed 


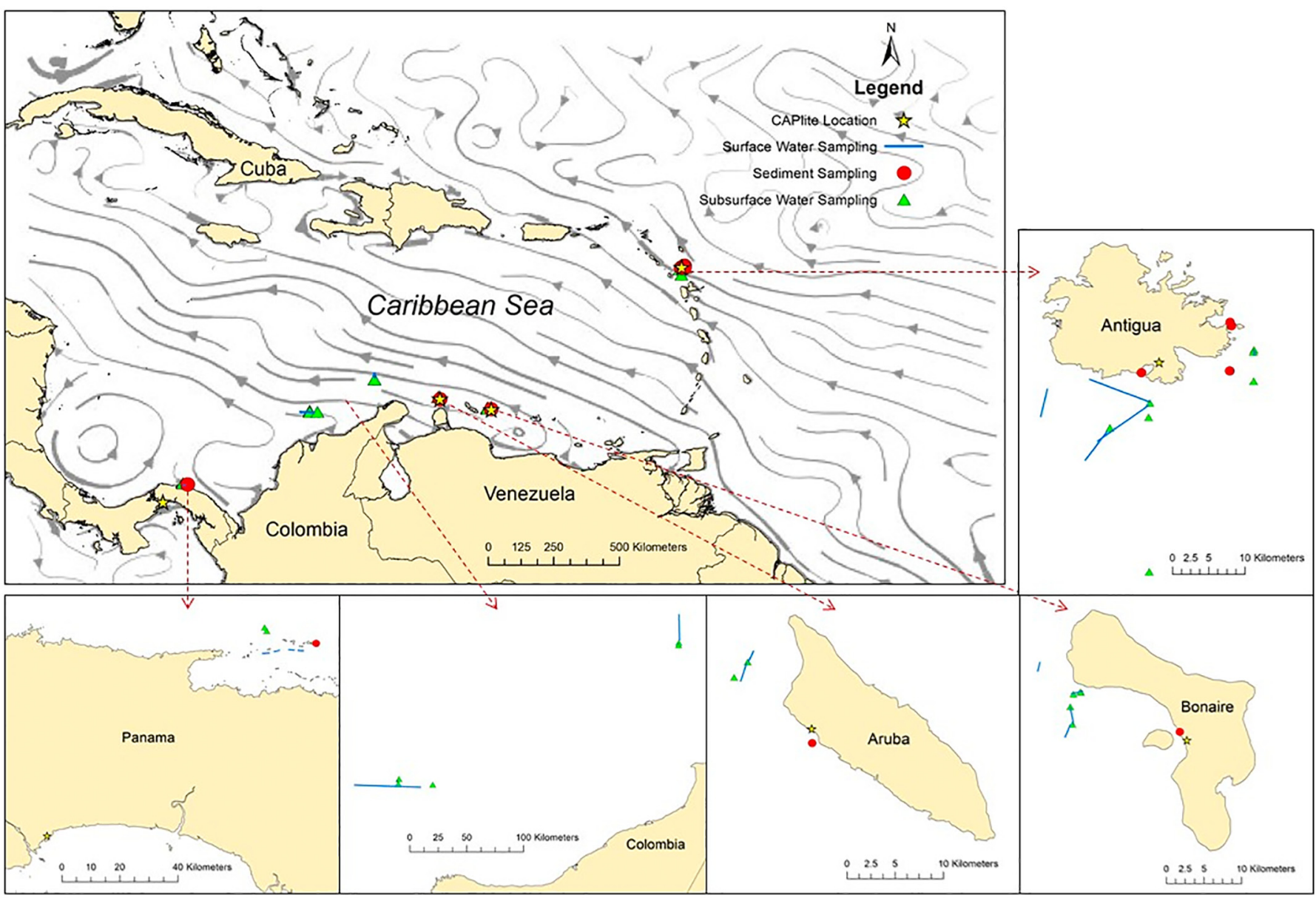

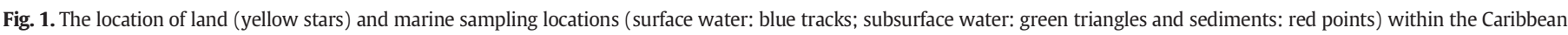

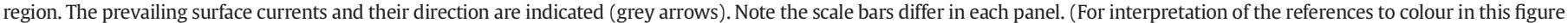
legend, the reader is referred to the web version of this article.)

to a depth of $25 \mathrm{~m}$, and a brass messenger weight was used to trigger and close the caps of the bottle before it was recovered to the surface. NIKSIN bottles were only deployed in Beaufort Sea state $\leq 2$. During sampling, the vessel was held stationary. The GPS location and time of deployment was recorded as was environmental data on the wind speed and direction. Once on-board, the NISKIN bottle was filtered below deck through a $20 \mu \mathrm{m}$ cellulose filter paper ( $\varnothing 70 \mathrm{~mm}$ ) using a stainless-steel hand vacuum filtration system. A clear-silicon tube was used to deliver the water from the NISKIN bottle into the filter funnel. Once the entire 51 volume of water had been filtered, the filter paper was immediately placed into a petri dish and sealed for further analysis at the University of Plymouth. This entire process was repeated for each of the triplicate samples, using a separate filter paper for each NISKIN bottle deployment.

\subsubsection{Sediment sampling}

Sediment samples were collected while the vessel was on anchor in natural or engineered marinas/anchorages. A $0.045 \mathrm{~m}^{2}$ OSIL stainless steel van Veen grab was utilised, with five replicates taken at each location $(n=6)$ within the Caribbean. At one location only 4 replicates were obtained due to the seabed substrate. The grab was thoroughly washed with ambient seawater between each deployment. Sediment from the centre of the grab, not in contact with the sides was transferred to a transparent polypropylene $110 \mathrm{ml}$ container using stainless steel spoons, which were also washed thoroughly in ambient seawater prior to, and between each sample being taken. The lids were immediately replaced on sample containers and the sediment was frozen at $-20^{\circ} \mathrm{C}$.

\subsection{Contamination controls}

Measures were taken to reduce contamination during sample collection and analysis. Sieves, used to sort the manta trawl samples, were backwashed thoroughly with the deck hose fitted with a $50 \mu \mathrm{m}$ aperture stainless steel mesh screen, prior to receiving each sample. Fibres were not included in manta trawl data; however, pieces of monofilament line were considered. During water filtration from the NISKIN bottles the funnel was kept covered with aluminium foil, apart from a small gap where the tube delivering water into the funnel was placed. Petri dishes remained closed apart from briefly to transfer the filter paper, whereupon they were closed and sealed immediately. Atmospheric controls were implemented during filtration, which involved placing a damped filter paper (11 $\mu \mathrm{m}$ aperture, $\emptyset 90 \mathrm{~mm}$ ) in an uncovered petri dish adjacent to filtration, to sample any airborne microplastics which may be deposited into our samples. A separate atmospheric control was used for each individual NISKIN bottle. For each polymer identified, the count on the atmospheric controls was subtracted from the raw count from each sample to obtain a blank-corrected count. Samples of all putative contaminants (manta trawl net, NISKIN bottle, lines and ropes, boat hull and deck paints etc) were collected and spectroscopically analysed concurrently with samples. Sample counts were adjusted where necessary, for any particles with colours and polymer types matching the contaminants. Laboratory procedural blanks for the sediment extractions (Section 2.3.1) were carried out, and polymer-corrections implemented where necessary. 


\subsection{Laboratory methods}

Analysis was performed in a positive pressure microplastics laboratory (air filtered to $0.5 \mu \mathrm{m}$ ) at the University of Plymouth. Personnel inside the laboratory were kept to a minimum and all wore natural fibre clothing under a cotton laboratory coat and specific laboratory shoes. Subsurface water filters and manta trawl samples were examined thoroughly under a Lumos dissecting microscope.

\subsubsection{Extracting microplastics from sediment}

Sediment samples were transferred to separate glass dishes and were dried for 10 days at $50{ }^{\circ} \mathrm{C}$. During drying the glass dishes were loosely covered with aluminium foil to prevent contamination but to allow moisture to escape. The samples were weighed to 2 d.p. prior to and after being dried. To isolate microplastics from dry sediment a modified version of the oil extraction protocol (Crichton et al., 2017) was used. Briefly, $20 \mathrm{~g}$ dry sediment was added to a $50 \mathrm{ml}$ centrifuge tube, to this $25 \mathrm{ml}$ of water and $1.5 \mathrm{ml}$ of rapeseed oil was added. The content of the tube was shaken vigorously for $5 \mathrm{~min}$ and was then centrifuged at $5000 \mathrm{rpm}$, for $5 \mathrm{~min}$, with a brake speed of 5 . The oil and aqueous layers were filtered under vacuum filtration through cellulose filter paper with $20 \mu \mathrm{m}$ aperture. The protocol was repeated to analyse each sediment sample in its entirety.

\subsubsection{Identification of microplastics}

Microplastics were classified based on their morphology as either i) fragment, ii) films, iii) monofilament line, iv) foam, v) pellets or vi) fibres (only counted for subsurface bulk sampling) (Hidalgo-Ruz et al., 2012). Sizes of plastics obtained in the manta trawls were categorised according to the sieve size fractions, while microplastics in subsurface water and sediment samples were measured using the ocular scale of the Lumos dissecting microscope, and then assigned to the same size classes used for surface sampling.

Microplastics ( $1 \mathrm{~mm}$ and $4.75 \mathrm{~mm}$ size fractions) collected during the manta trawls were identified using a PerkinElmer Spectrum Two attenuated total reflectance Fourier Transform infrared (ATR-FTIR) spectrometer. Each spectrum was the average of four co-added scans in the range $400-6000 \mathrm{~cm}^{-1}$ wavenumbers, with a background scan performed prior to each sample. The spectral resolution was $0.5 \mathrm{~cm}^{-1}$. Data were compared against the inbuilt PerkinElmer 'Polymer' spectral library to facilitate sample identification. Microplastics sampled by manta trawl which were retained on the $0.335 \mathrm{~mm}$ sieve, along with those sampled from subsurface water and sediments were analysed with a Bruker Vertex $70 \mu$ FTIR coupled with a Bruker Hyperion 1000 microscope in transmission mode. Each spectrum and background scan were the average of 32 co-added scans in the wavenumbers $600-4000 \mathrm{~cm}^{-1}$. Microplastics were analysed on a diamond compression cell (Specac DC2; 2 mm diameter). Spectra were visualised in the complimentary OPUS v7.5 software, manually inspected and compared against the 'BPAD' and 'synthetic fibres' spectral libraries.

\subsection{Statistical analysis}

Pearson correlations were applied to determine any influence of environmental variables on the concentration of microplastics within each environmental compartment (surface water, subsurface water and sediment). A Kruskal-Wallis analysis of variance followed by Dunn's post hoc test (Dinno, 2017) was used to examine statistical differences in the abundance of surface water microplastics between countries. Permutational multivariate analysis of variance (PERMANOVA) was used to test the null hypothesis that there was no significant difference in polymer composition according to environmental/sampling factors or between countries. Pearson correlation test was used to examine the relationship between factors and in this case wind speed and sea state were correlated and wind speed was subsequently omitted. Surface water and subsurface water were considered separately, due to low replication PERMANOVA could not be applied to sediment. For surface water the factors were transect, country, water volume sampled and sea state. For subsurface water the factors were transect, country and sea state. The polymer composition analysis was based on a BrayCurtis dissimilarity matrix. The statistical significance of the variance components were tested using 9999 permutations and the null hypothesis was rejected when the significance level (p) was $<0.05$. Statistical analyses were performed in R v1.3.1093 (R Core Team, 2019) using the packages vegan (Oksanen et al., 2019), dplyr (Wickham et al., 2020) and dunn.test (Dinno, 2017). Unless otherwise stated, the standard deviation of the mean has been reported when \pm is given.

\subsection{Land-based surveys}

A condensed version of the Circularity Assessment Protocol (CAP), which was developed by the Circularity Informatics Lab at the University of Georgia (UGA), was performed in Antigua, Bonaire, Aruba and Panama in November and December 2019. In this case, one portion of the CAP was used to collect localised data that serves as a baseline for characterizing the leakage of plastic and other materials in a community. Further details on the CAP can be found at circularityinformatics.org.

Three principal transects and three backup transects were randomly selected (within restraining parameters) by the UGA team for each location. Site selection criteria were as follows; i) the selected site was accessible from the marina. As such, the data does not characterise the community as a whole, but provides information about the neighbourhood in the immediate vicinity of the marina. ii) The population density of study sites, which was extracted from LandScanTM (https://landscan.ornl.gov/), was limited to the most densely populated 5 th of the community area. Coverage of the most densely populated areas of each community was dependent upon the distribution of the population.

From the most densely populated areas, three circular areas $1 \mathrm{~km}$ in diameter were randomly generated for field sampling. Within each field sampling sites, teams aimed to conduct a minimum of three $1 \mathrm{~m} \times 100$ transects, totalling 9 transect per community, using the Marine Debris Tracker app to record data. However, due to unforeseen circumstances, some sites collected more or less than three transects of data, and therefore sample sizes vary.

Within the transects the teams documented every visible item of litter, locations of stores, vendors and restaurants, locations of schools, parks, and religious centres, formal and informal waste management infrastructure, waste piles, and storm water infrastructure. The team logged the litter items based on the item names and associated material categories in the Marine Debris Tracker app (e.g. a "Plastic Food Wrapper" in the "Food Plastic" material category, see full list in SI Table 4). All of the data was stored in the open source and freely available Marine Debris Tracker database (debristracker.org) and analysed post-expedition by the UGA team.

\subsection{Lagrangian particle tracking}

To identify the potential origins of the plastics retrieved in the surface water trawls a hindcast 2D Lagrangian modelling approach was used. Velocity fields for the period 01/09/2019 00:00:00 to 01/01/ 2020 00:00:00 were provided by the GOFS 3.1: 41-layer Hybrid Coordinate Ocean Model (HYCOM) + Navy Coupled Ocean Data Assimilation (NCODA) based ocean prediction system output, obtained from the HYCOM OpenData server (hycom.org/dataserver/). This ocean model provides 3 hourly surface velocities on a global grid ( $80 \mathrm{~S}$ to $90 \mathrm{~N}$ ) with a grid scale of $0.08^{\circ}$ longitude by $0.08^{\circ}$ latitude. Particles were released from each of the 19 sampling locations at the given time of sampling (see Table SI Table 1) and were backtracked for 60 days using the Lagrangian ocean analysis framework, Parcels (v2.0: (Delandmeter and van Sebille, 2019)). Particles were advected using a 4th order Runge-Kutta advection scheme and stochastic diffusivity was implemented using a scaled random walk. Multiple particles were released from each site so that variation in dispersal resulting from the diffusive component of the model could be explored. In post-processing, each 
model run was standardised so that simulation duration was based on time rather than date. To determine whether a particle was backtracked to land, and the timescale of this, a global land mask function was used in Python 3.8 (Karin, 2020). When a particle reached land, the town and country of the particle location was obtained in Python using 'Openstreetmaps' API, the duration taken for the particle to back-track to land and the Euclidean distance travelled by the particle are recorded.

\section{Results}

\subsection{Plastics in surface waters}

Plastics were identified in every manta trawl conducted except two; one of which was located in Antiguan water and one was off the coast of Colombia. The frequency of plastics differed between trawls and countries (Fig. 2). The greatest quantity of plastics (486 pieces equating to $5.09 / \mathrm{m}^{3}$ ) was located around the San Blas islands, Panama. When grouping trawl data by country, the water sampled around Panama had significantly more microplastics than Antigua $(p=0.031)$, Bonaire $(p=0.039)$ or Colombia ( $p=0.007$ ), however it is noted that trawls around Panama occurred in sea states of ' 0 ', while sea states of 1 and 2 were recorded for other sampling locations (Fig. 2). Sea state was the only environmental variable found to have a significant negative relationship with the quantities of microplastics detected (Pearson's $\mathrm{p}, \mathrm{r}=-0.5, \mathrm{p}=0.04$ ).

A total of 18 polymers (including two co-polymers) were identified in Caribbean Sea surface water (Fig. 3). PERMANOVA analysis indicated that the composition of polymers differed significantly $\left(\mathrm{F}_{\text {model }}=1.698\right.$, $\mathrm{p}=0.027$ ) between countries. For example, paint flakes, polyamide (PA) and polyethylene (PE) were found in all countries, however the prevalence of PE was lower in Antigua (only in 1 out of 5 trawls) than in other countries where PE was consistently recorded. Polypropylene (PP) was present in all country's waters apart from Aruba. Other polymer types had more localised occurrence, for example polyester was identified around Antigua and Panama only, polycarbonate only around
Antigua, and acrylonitrile was only identified in the most western of our survey sites, around Colombia and Panama.

Fragments were the most abundant morphology (SI Fig. 1), accounting for between 40 and $100 \%$ of the plastic pieces within each trawl sample. Plastic pellets were documented only in two samples, one from Antigua ( 0.014 pellets $\left./ \mathrm{m}^{3}\right)$ and one from Panama $\left(0.774\right.$ pellets $\left./ \mathrm{m}^{3}\right)$. Foam (expanded PS) was present in at least one sample from each country's waters in concentrations ranging between 0.003 and $0.889 / \mathrm{m}^{3}$ recorded in Antigua and Panama respectively. Large plastics pieces $(>4.75 \mathrm{~mm}$ ) were infrequently recorded and were only present in three trawls (SI Fig. 2), with the most numerically dominant size of plastics was the fraction $1 \mathrm{~mm}-4.74 \mathrm{~mm}$ in size, and the most frequently identified within trawls (present in 16 of the 19 samples) was the size category 0.335-0.99 mm.

\subsection{Microplastics in subsurface waters}

Microplastic data were polymer-corrected based on counts and composition recorded in the atmospheric controls and putative contaminants sampled from the yacht. The majority of the particles isolated were fibrous ( $\mathrm{n}=91 ; 85 \%$ ) with the remaining items categorised as fragments ( $n=16,15 \%)$. Of the fibres, the majority were cellulosic in their origin ( $\mathrm{n}=77,85 \%$ of fibres; SI Fig. 3 ) with the remaining synthetic items ( $n=14,15 \%$ of fibres) comprised of acrylic, polyester, polyamide and polypropylene. In addition, fragments $(n=16)$ identified as paint, PVC, PA, polyester were also identified. Deployments from Panama contained the greatest quantities of synthetic polymers (av. $0.53 / 1 \equiv 533 / \mathrm{m}^{3}$ ), while Bonaire had the lowest (av. 0.067/1 $\equiv 67 / \mathrm{m}^{3}$ ). Correlation analysis indicated that there was no significant relationship between wind speed or sea state and the quantity of particles.

The diversity of polymers identified in subsurface water was much lower than in surface water. In addition to cellulosic fibres, which were coloured implying they were likely regenerated/processed, a total of 6 synthetic polymers were isolated from the subsurface samples

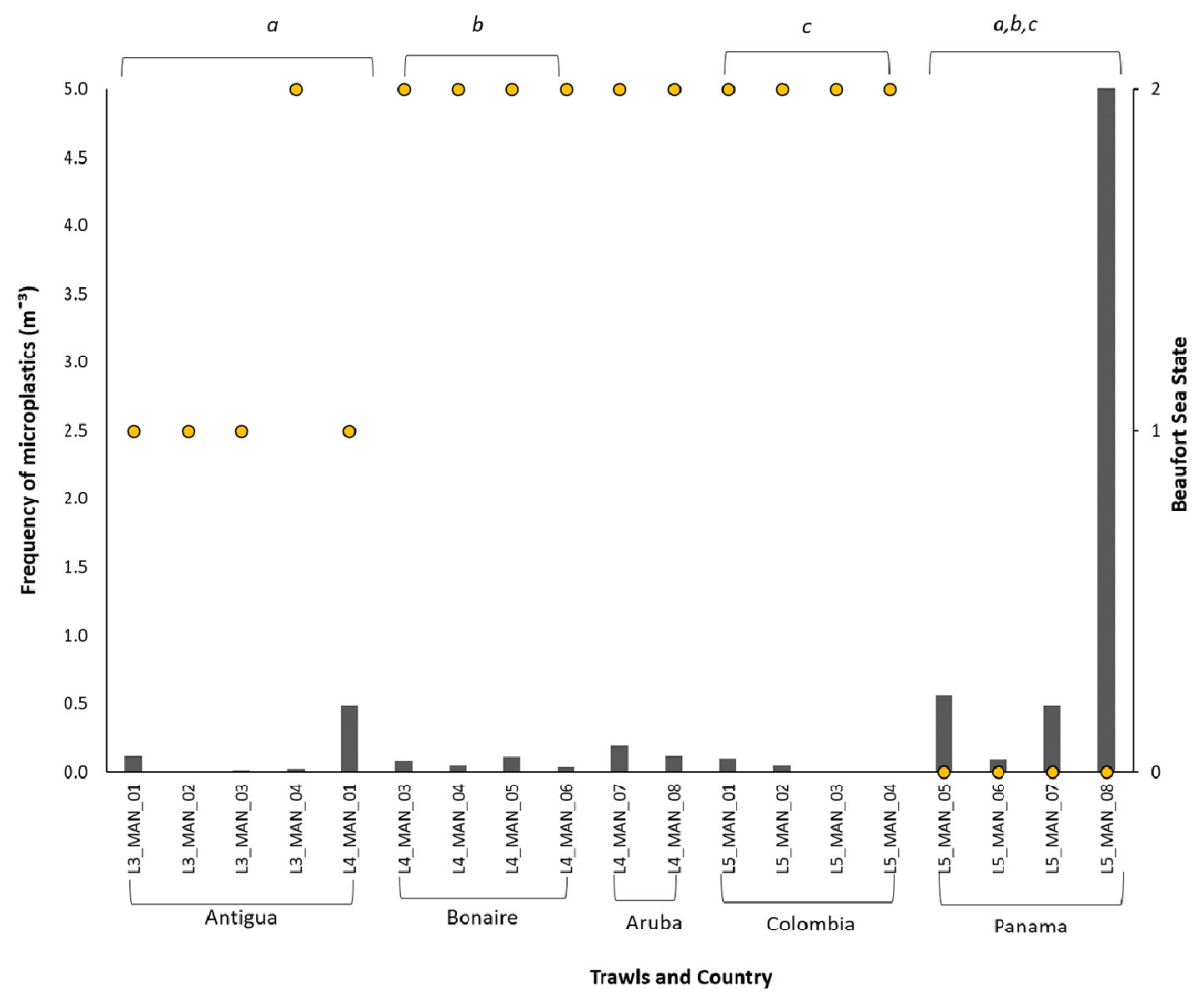

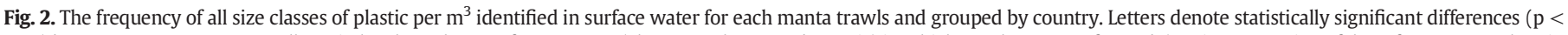

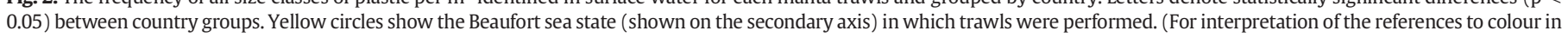
this figure legend, the reader is referred to the web version of this article.) 


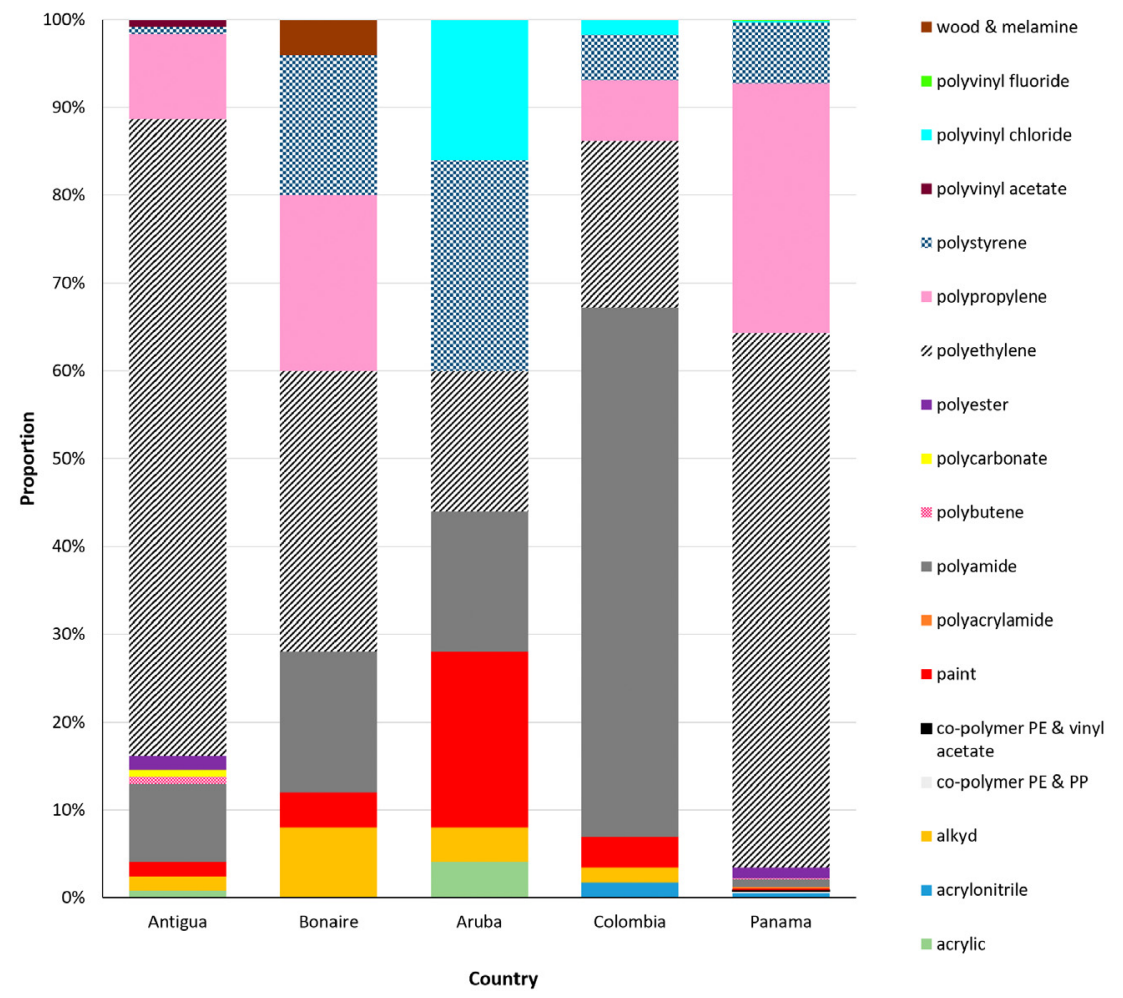

Fig. 3. Polymer types (percentage of the total) identified in surface waters of the different countries sampled.

(Fig. 4). PERMANOVA analysis indicated that the composition of polymer types differed significantly $\left(\mathrm{F}_{\text {model }}=2.29, \mathrm{p}=0.035\right)$ between countries. PP was only identified in Antiguan waters and in contrast to surface water and sediment samples, polyethylene was not identified in subsurface water samples.

On average, synthetic particles were smaller $(0.867 \mathrm{~mm} \pm 1.050)$ in their size than cellulosic particles ( $1.089 \mathrm{~mm} \pm 0.719$ ) (SI Fig. 4). Across all of the countries, the quantities of synthetic microplastics were two orders of magnitude greater in subsurface water samples $\left(33 \mathrm{MP} / \mathrm{m}^{3}\right)$ than in surface waters $\left(0.40 \pm 1.21 \mathrm{MP} / \mathrm{m}^{3}\right)$.

\subsection{Microplastics in sediment}

Five replicate samples were obtained for each location, apart from L4_sed_3 where four replicates were collected due to seabed substrate.
Overall, the greatest abundance of microplastics was recorded in the sample from Aruba $(0.13 \pm 0.10 \mathrm{MP} / \mathrm{g})$, and the lowest reported in Panama ( $0.03 \pm 0.003 \mathrm{MP} / \mathrm{g})$. Analysis indicated there was no correlation between environmental variables (sea state or water depth) on the quantity of microplastics in sediments. A total of 9 polymers were identified; polypropylene was identified in the highest abundance in all samples (Fig. 5). While the polymer composition could not be statistically tested between locations due to sample sizes, the greatest diversity of polymers was observed in the samples collected from Antigua. Acrylic, acrylonitrile butadiene styrene, polyacrylic and polystyrene were unique to sediments collected from Antigua (Fig. 5).

Fragments were the most abundant morphology isolated from samples collected around Antigua (52-93\%) and Panama (73\%) (SI Fig. 5), while in Aruba monofilament line composed of polypropylene accounted for $60 \%$ of the microplastics. Plastics ranged in size between

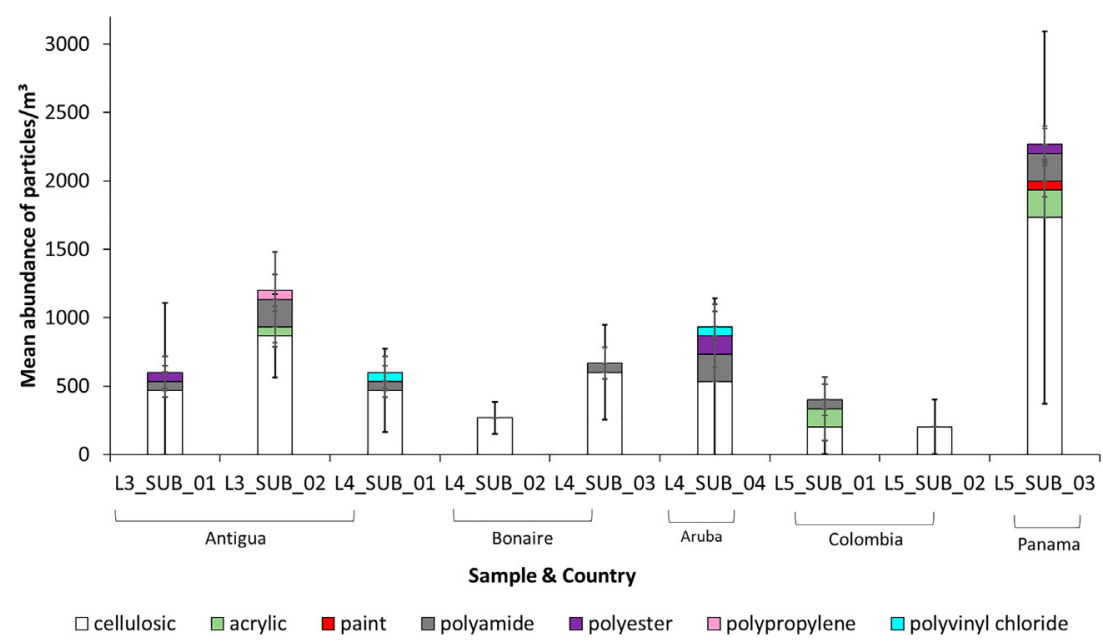

Fig. 4. The mean abundance $\left(\mathrm{n}=3\right.$ ) of polymers per $\mathrm{m}^{3}$ sampled from a depth of $25 \mathrm{~m}$ at each site and country. Error bars denote standard deviation. 


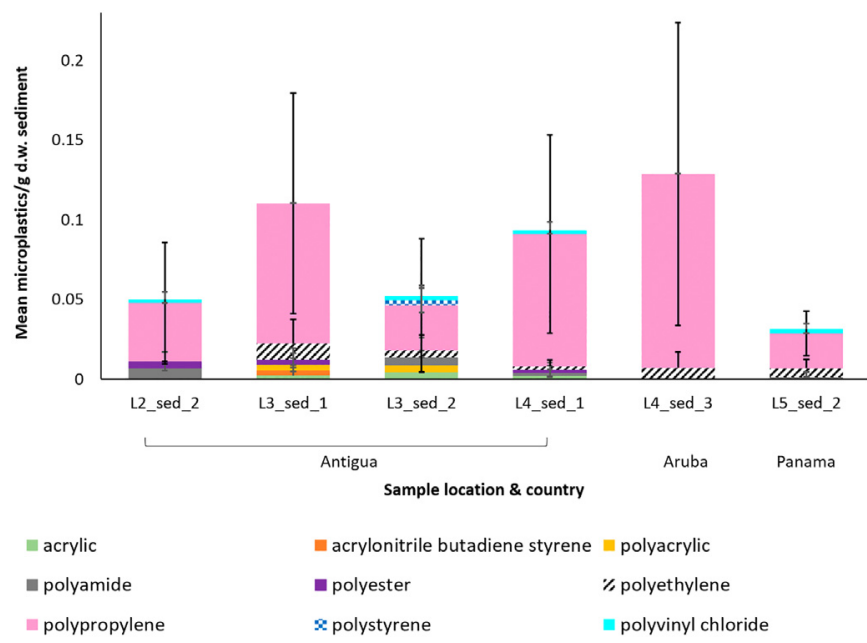

Fig. 5. The mean polymer composition/g dry weight sediment. Error bars show standard deviation.

0.08 and $14.0 \mathrm{~mm}$, however the majority (59\%) were between 0.335 and $0.999 \mathrm{~mm}$ in size (SI Fig. 6).

\subsection{Land-based surveys and overview of local policy}

The litter data collected via the Marine Debris Tracker app as part of the land-based survey methodology yielded information regarding the composition of waste that ends up in the environment in the immediate vicinity of the marinas along the eXXpedition route. Overall, cigarettes were the most numerous litter item in every country except for Antigua, where hard plastic fragments dominated. Hard plastic fragments and plastic food wrappers were among the most commonly identified litter items in every country surveyed (Table 1 ), and all countries surveyed except Panama had plastic fragments (of a range of morphologies) within their top two litter categories. The litter found in the surveys also appears to be linked to plastic consumer goods, which are largely lightweight packaging that is optimal for import and on which island nations rely heavily. Detailed country specific data are available in SI Figs. 7-10.

\subsubsection{Antigua}

Six $100 \mathrm{~m}$ litter transects were conducted in Antigua. Sheetlike plastic fragments were the most numerous litter item documented, and fragments in general constituted the most abundant litter category recorded (37\% of items), followed by food plastics. Of the countries sampled, Antigua was the only one that had plastic rope among its top litter items (Table 1 and SI Fig. 7). Antigua was also the only country

Table 1

The top 5 numerically abundant litter items and the average density of all litter recorded within each country sampled.

\begin{tabular}{|c|c|c|}
\hline $\begin{array}{l}\text { Country } \\
\text { (\# of transects) }\end{array}$ & Top 5 most abundant litter items & $\begin{array}{l}\text { Average } \\
\text { litter density }\end{array}$ \\
\hline $\begin{array}{l}\text { Panama } \\
(\mathrm{n}=6)\end{array}$ & $\begin{array}{l}\text { 1) Cigarettes, 2) Plastic food wrapper } \\
\text { (multilayer), 3) Hard plastic fragments, 4) } \\
\text { Threadlike plastic fragments, 5) Other paper } \\
\text { 1) Cigarettes, 2) Hard plastic fragments, 3) Plastic }\end{array}$ & $\begin{array}{l}0.475 \\
\text { items } / \mathrm{m}^{2}\end{array}$ \\
\hline $\begin{array}{l}\text { Bonaire } \\
(\mathrm{n}=3)\end{array}$ & $\begin{array}{l}\text { food wrapper (multilayer), 4) Plastic bottle cap, } \\
\text { 5) Sheetlike plastic fragments } \\
\text { 1) Cigarettes, 2) Hard plastic fragments, 3) Paper, }\end{array}$ & $\begin{array}{l}0.7133 \\
\text { items } / \mathrm{m}^{2}\end{array}$ \\
\hline $\begin{array}{l}\text { Aruba } \\
(\mathrm{n}=2)\end{array}$ & $\begin{array}{l}\text { 4) Plastic food wrapper (multilayer), 5) Foam or } \\
\text { plastic cups/lids } \\
\text { 1) Sheetlike plastic fragments, 2) Other paper, 3) }\end{array}$ & $\begin{array}{l}2.520 \\
\text { items } / \mathrm{m}^{2}\end{array}$ \\
\hline $\begin{array}{l}\text { Antigua } \\
(\mathrm{n}=6)\end{array}$ & $\begin{array}{l}\text { Plastic food wrapper (multilayer), 4) Hard plastic } \\
\text { fragments, 5) Plastic rope }\end{array}$ & $\begin{array}{l}0.536 \\
\text { items } / \mathrm{m}^{2}\end{array}$ \\
\hline
\end{tabular}

where tobacco products (encompassing cigarettes, packaging and lighters) constituted less than $20 \%$ of the litter in terms of categories - all other countries had tobacco products as their most frequent category identified (Fig. 6).

Antigua and Barbuda have a relatively low percentage of mismanaged waste (3.2\%) and per capita waste generation rate $(0.90 \mathrm{~kg} /$ person/day) (IDB, 2020). It has been estimated that Antigua and Barbuda's waste collection services serve $98.61 \%$ of the population and therefore there are very low estimates of waste leakage (3.2\%) (Luken, 2017). Antigua and Barbuda also instituted a National Plastic Bag Ban in 2016 and a ban on Expanded Polystyrene in 2017 (SI Table 5).

\subsubsection{Aruba}

Two $100 \mathrm{~m}$ litter transects were conducted in Aruba, which differed greatly in the number of litter items, and therefore may not present representative data for the area. The data from Aruba were unique in that there was a high prevalence of glass fragments, which originally represented the top litter item documented. Upon further investigation, it appeared that the fragments were localised and were likely from a broken glass bottle. Cigarettes were the most frequently encountered litter item, with hard plastic fragments the next most documented.

Compared to other Caribbean countries, Aruba has a mid - high percentage of mismanaged waste (21.6\%) and a higher than average per capita waste generation rate $(2.91 \mathrm{~kg} /$ person/day) (IDB, 2020). It is estimated that $12.4 \%$ of the waste stream in Aruba is composed of plastic. In 2016, Aruba, along with Bonaire and Curacao, convened and established the Caribbean Waste Collective with the goal of increasing inter-island cooperation to stimulate a new economy that views waste as a valuable and profitable item, which has also included increased Recycling infrastructure and industry (Luken, 2017).

\subsubsection{Bonaire}

Three $100 \mathrm{~m}$ litter transects were conducted in Bonaire. The top three most prevalent litter categories were closely balanced between tobacco products, plastic fragments, and food plastic. As for the individual items, cigarettes dominated the composition by a large margin. There was a high prevalence of fragments among the top items, including both hard and sheetlike plastic fragments. Bonaire was the only country where bottle caps were listed among the top five litter items (Table 1).

Bonaire's Department of Space and Development proposed legislation in 2018 that would ban certain types of single-use plastic, which is currently awaiting approval and the State Secretary of the Netherlands has expressed support in improving waste management infrastructure and policy in Bonaire in the coming years (Davies, 2020).

\subsubsection{Panama}

Six $100 \mathrm{~m}$ litter transects were conducted in Panama. The litter transects were conducted on the Pacific coast while the marine samples were collected on the Caribbean coast of Panama. The most abundant category of litter was tobacco products (encompassing cigarettes and associated packaging and lighters) and the count of tobacco products was higher in Panama than in any other country (Fig. 6). Cigarettes were the dominant litter item documented by a relatively high margin (by 63 items, SI Fig. 8). Like in the other countries surveyed, there was a high prevalence of plastic fragments, including both hard plastic fragments and threadlike fragments; the latter of which could suggest association fishing or with fabric/clothing. Food plastic was the third most prevalent category documented.

Of the four countries sampled, Panama has the highest estimated mismanaged waste (44.3\%), but a comparatively low to average per capita waste generation rate (1.03 kg/person/day) and percentage of plastic in the waste stream (12\%) (IDB, 2020). Panama is also unique among the countries sampled in that it has government support for the informal recycling sector, as well as the Pepsico sponsored 'Recycling with Purpose (PepsiCo, 2019)' program which could also explain why larger and more 


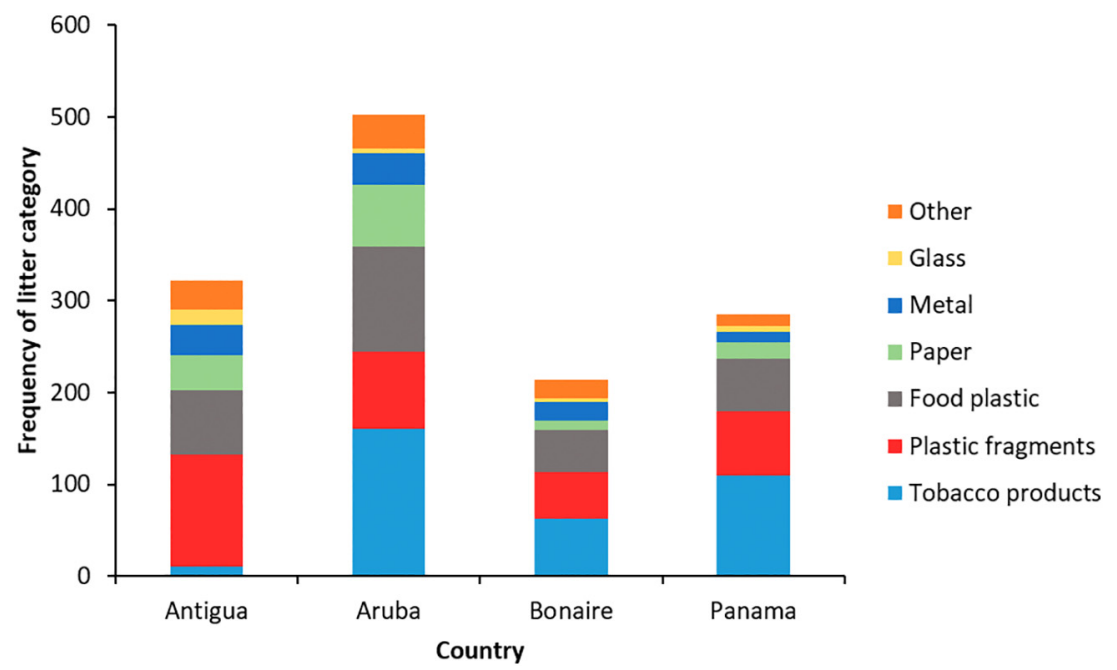

Fig. 6. The frequency of litter categories recorded within each country sampled.

readily recycled plastic items were not found among the litter items in Panama. For example, only 1 PET bottle was documented among the 285 litter items in Panama. In 2018, Panama also became the first Central American country to implement a plastic bag ban (Karasik et al., 2020) and in 2020 a second ban for single use articles (including cotton swabs, straws, plastic cutlery and food containers) was approved by the government (República de Panamá, 2020).

3.5. Lagrangian particle tracking: the potential geographic sources of marine microplastics

The majority of simulated particles (80\%) were back-tracked to land within the 60-day model simulation (SI Table 6). On average, it took particles $11 \pm 12.98$ SD days to reach land. For the Antiguan samples, $66 \%$ of particles backtracked did not reach land within the 60 -day simulation. Those that did reach land in $\leq 1.2$ days, suggesting some short term self-seeding of marine litter to Antiguan waters, however the model suggests that the majority of plastics sampled in this area have travelled from the East, i.e. the Atlantic Ocean (Fig. 7).

All particles released at the Bonaire sampling sites were backtracked to land within 6 days and all were traced back to Bonaire itself (Fig. 7). A similar occurrence was observed in particles released from the Aruba sites, with $85 \%$ of particles being backtracked to the Aruban shoreline in $<1$ day (Fig. 7). The potential source of the remaining $15 \%$ of particles was found to be the Federal Dependencies of Venezuela, with particles traveling a distance of $439 \mathrm{~km} \pm 4 \mathrm{~km}$ over 33 days \pm 1.77 days. Venezuela was also predicted to be a predominant potential source location for the plastic collected off the coast of Colombia with $40 \%$ of all particles being tracked to the Falcón region. Most other particles seeded in Colombian waters could be traced back to Colombia, with La Guajira being a considerable potential source location.

Finally, the model predicted the majority of the litter in the water around the San Blas islands to come from mainland Panama, with $72.5 \%$ of particles being traced back to the Comarca Guna Yala region.

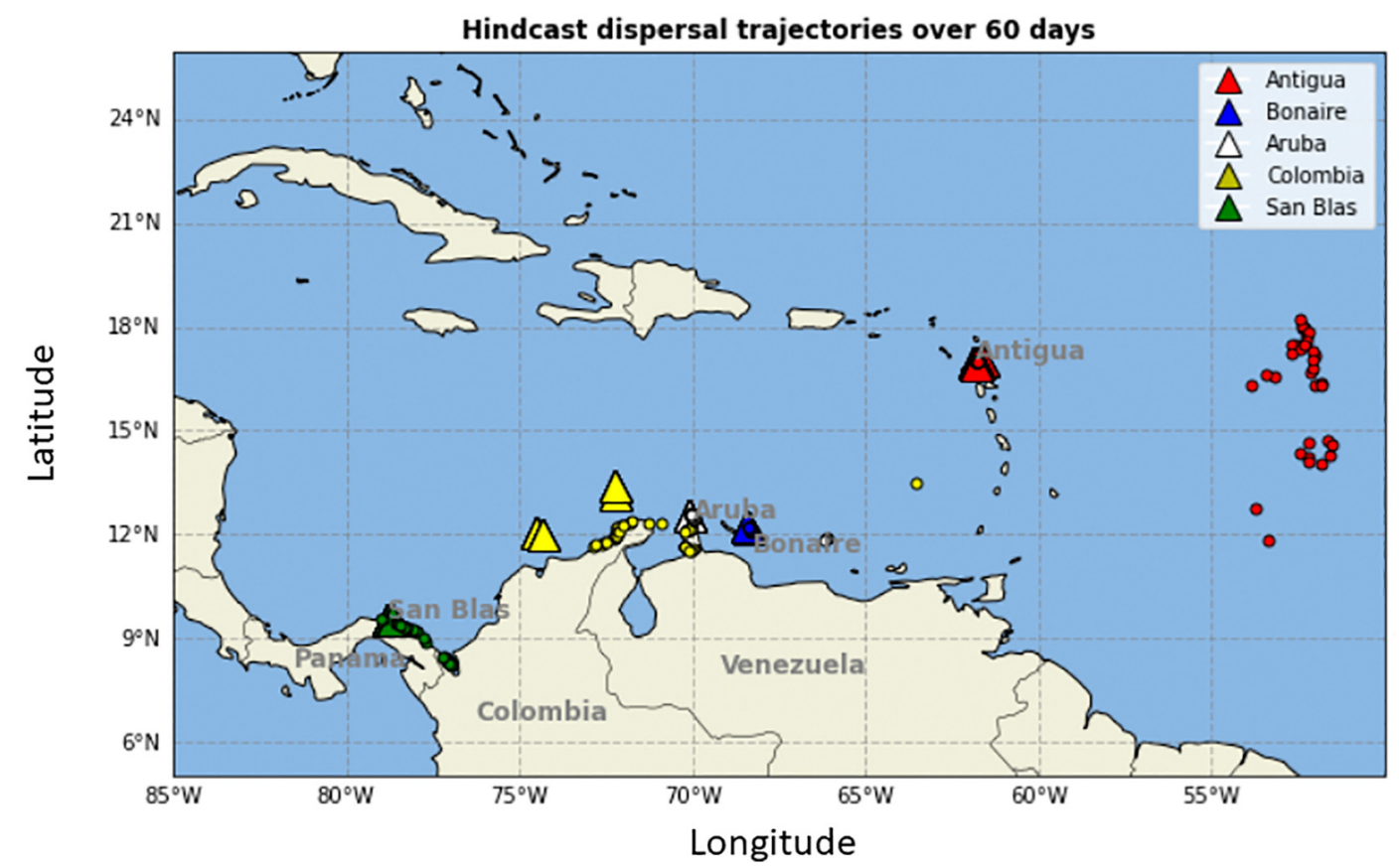

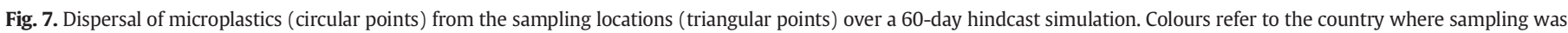
conducted. 
Of the remaining particles, 10\% were each traced back to the Chocó and Córdoba regions of Colombia respectively, and 7.5\% did not reach land with the 60-day model simulation.

\section{Discussion}

This study provides baseline data on the abundance of (micro)plastics within different environmental compartments in the Southern Caribbean region and examines their potential origins through landbased assessments and Lagrangian modelling approaches; an interdisciplinary approach absent from plastic pollution research. Evidence of the abundance of plastics within the Caribbean's marine environment are lacking, and to this end the data presented give a holistic approach to examine the potential origins, flows and quantities of plastics within the Southern Caribbean.

Previous research has documented macro and microplastics in beach sediments (Bosker et al., 2018; Mazariegos-Ortiz et al., 2020; de Scisciolo et al., 2016; Delvalle de Borrero et al., 2020) from the Caribbean region, yet few have assessed those in the marine ecosystem (KutralamMuniasamy et al., 2020). In this study, the quantities of microplastics varied considerably between different environmental compartments and locations, i.e. individual samples within countries and between countries. For example, while different sampling methods were utilised between surface and subsurface sampling which may result in differences in the quantities of microplastics collected, particularly fibres; on average the abundance of synthetic plastics were two orders of magnitude greater within water collected at $25 \mathrm{~m}$ than in surface waters. This finding is contrary to observation from the upper North Atlantic gyre where particle count decreased with depth (Reisser et al., 2015). Additionally variation was noted between sediments and surface waters. Panama had the lowest concentrations of microplastics in sediment samples, while the highest quantities of surface water plastics. Conversely sediment from Aruba had the highest microplastics load while the lowest surface water concentrations. These findings warrant further work to examine plastic pollution over larger spatial scales within territorial water and elucidate any localised influences on the sinking of plastic particles.

Of the regions studies, the San Blas islands, Panama had the highest abundance of microplastics present at a water depth of $25 \mathrm{~m}(0.89 \mathrm{MP} / \mathrm{l})$ and significantly greater quantities in surface water (average $1.56 \pm$ $2.36 \mathrm{SD} . \mathrm{MP} / \mathrm{m}^{3}$ ) than recorded in the other countries sampled. It is important to note that the lightest wind and lowest sea state was recorded during these sample collections. A statistically significant negative relationship was identified between sea state and the concentration of microplastics in surface waters, which may explain the patterns we observed. Larger waves (indicative of sea state) and higher wind speeds will increase surface water mixing and redistribute plastics into the ocean interior (Kukulka et al., 2012). Further sampling campaigns undertaken within the Southern Caribbean would be beneficial to establish whether there are differences in the quantities of plastic between countries or whether this is an artefact of environmental conditions.

Linking environmental data with Lagrangian particle modelling, a technique which has been widely utilised to inform on the likely sources and transport of marine plastic pollution (Lebreton and Borrero, 2013; Hardesty et al., 2017; Kaandorp et al., 2020), attempts to indicate potential origins for the marine plastics identified within this study. The majority of the plastics collected within this study from the water around Bonaire, Aruba, Colombia and Panama were tracked back to the country itself, suggesting leakages of plastic waste from land or the mobilisation of beached debris from their shorelines. In 2020, daily waste generation rates per capita were estimated to range between 0.76 and $2.91 \mathrm{~kg} /$ person/day for Aruba, Colombia and Panama (data not available for Bonaire) which are slightly higher than the $0.99 \mathrm{~kg} /$ person/day average for the Latin America and Caribbean region. Annual quantities of mismanaged waste was estimated at $21.6 \%, 6 \%$ and $44.3 \%$ for each country respectively (IDB, 2020), and indicates waste leakages, of which plastic is a major component (IDB, 2020). Research conducted along the Caribbean coast of Colombia support this. The majority of beaches studied along northern Colombia were classified as 'high' or 'very high' in terms of their microplastic pollution (Rangel-Buitrago et al., 2021), with the greatest accumulations and leakages of plastics linked to river discharge (Rangel-Buitrago et al., 2021), local currents (RangelBuitrago et al., 2019), increased tourism and poor waste management (Garces-Ordonez et al., 2020b; Garces-Ordonez et al., 2020a).

Particle modelling revealed a different pattern for Antigua compared to the other countries. While a small proportion of the particles were traced back to Antigua itself, the majority of the trajectories indicate transport from the wider North Atlantic Ocean, suggesting distant sources and to a slightly lesser extent local sources, contribute to the plastics found in Antigua's coastal marine environment. Antigua had among the lowest terrestrial litter density, relatively low waste generation rates compared to other Caribbean countries (3.2\%) (IDB, 2020) and some of the lowest quantities of surface water microplastics yet a high diversity of polymers were recorded. Integrating these datasets further supports that plastics located around Antigua may have been transported via Atlantic Ocean currents and from leakages from the North Atlantic sub-tropical gyre, as also evidenced for other eastern Caribbean countries (Ambrose et al., 2019; Davranche et al., 2020).

Plastic pellets were identified in surface water samples collected around Antigua ( 0.01 pellets $/ \mathrm{m}^{3}$ ) and Panama $\left(0.77\right.$ pellets $\left./ \mathrm{m}^{3}\right)$. Pellets collected around Antigua appeared discoloured inferring prolonged environmental weathering and long-range transport. Conversely the majority of the pellets around Panama had little evidence of degradation (e.g. pristine white colour) suggesting localised sources, such as the plastic production facilities located in the industrialised Cartagena region of Colombia. Other studies have evidenced relatively high densities of new white pellets beached in Cartagena (Acosta-Coley et al., 2019a; Acosta-Coley et al., 2019b) and found greater quantities of pellets present along the Caribbean coast of Panama than the Pacific coast (Delvalle de Borrero et al., 2020) suggesting their transport in northwesterly currents from Colombia to Panama, and corroborating our model predictions.

The high proportions of fragmented plastic identified in both the land and marine samples suggest degradation through environmental exposure and/or ocean transport. This is supported by the particle modelling which indicates that for all countries sampled a combination of local (i.e. the country itself) and more distant sources contribute towards the environmental plastics identified. It is important to note that the model does not consider the remobilisation and redistribution of beached plastics which could have originated from elsewhere, processes which may also cause fragmentation. Quantities of plastic debris and the factors influencing its distribution can vary even over small geographic areas largely associated with prevailing wind and ocean circulation (Ambrose et al., 2019). For example, greater quantities of beached litter have been recorded on windward coastlines than on leeward facing coastlines (de Scisciolo et al., 2016). As such, our results may be somewhat localised to the sample points studied and may not be representative of the country as a whole. The findings do however highlight the transboundary movements of plastics between Caribbean countries which may undermine local policies to tackle plastic pollution.

Furthermore, challenges can be presented when trying to tackle plastic pollution associated with and arising from industries on which nations depend upon heavily, such as tourism. With an estimated 31.5 million tourists in 2019 (Caribbean Tourism Organisation, 2020), travel and tourism contributed an estimated $\$ 59$ billion to the economy of the Caribbean region, representing nearly $14 \%$ of the region's GDP (World Travel and Tourism Council, 2020). However, tourism in the Caribbean has significant impacts on waste management practices in the region, and globally studies have suggested that solid waste generation in the tourism sector can put significant stress on municipal solid waste management systems and in some cases can account for higher per capita waste generation than other industries or residential areas 
(Bashir and Goswami, 2016; Saito, 2013; Mateu-Sbert et al., 2013). Many of the polymers identified in the water and sediment samples, e.g. fragments and films of PE and PP, and PS fragments and foams, have applications within consumer products such as food and beverage packaging. Food packaging items were routinely found during terrestrial surveys, which when coupled with pressures on waste management infrastructure within the Caribbean region may result in leakage into the marine environment.

Paint particles were identified in the water of all regions sampled, which could have been shed from the hulls of vessels while in transit (Dibke et al., 2021), or when carrying out maintenance (MullerKaranassos et al., 2019; Turner, 2010). The paint fragments were distinct in their colour and FTIR spectra to any of the paints used on S.V. TravelEdge precluding their source as contamination. Further, rope debris was identified within the most common street litter items in Antigua. Ropes are commonly made of polyester, polypropylene and polyamide, and all three polymers were found within sediment and water column samples suggesting they may have arisen from the maritime sector. In particular PP dominated the polymer composition across all the sediment samples collected, despite its inherent density being less than seawater, meaning it will naturally float (Andrady, 2011). The Caribbean is a renowned destination for nautical tourism with $>30$ million passengers arriving by cruise ships (Caribbean Tourism Organisation, 2020) and $>130,000$ by yacht/leisure craft (Zappino, 2005; Phillips, 2014), which may play a role in the origin of these particles.

As highlighted in this study, combining terrestrial litter data with marine sampling is advantageous to consider the potential flows of plastic pollution. The portion of the Circularity Assessment Protocol utilised was an abridged version of the full methodology, and limitations arise from the relatively small number of transects conducted meaning data are not fully representative of the geographic areas as a whole. However, based on other studies and complimentary data, such as waste generation rates and waste management infrastructure the findings presented are in accord with expected patterns in the region. Litter estimates recorded during land-transect are similar to those documented in the Caribbean previously, which are higher than the global average of 573 items $/ \mathrm{km}$ (Diez et al., 2019).

Litter data can also be used to evaluate plastic reduction interventions. Over 20 Caribbean countries already have some form of national plastic policy in place (Karasik et al., 2020) (see SI Table 5), the majority of which are plastic bag bans, and another 8 countries are currently in discussion to develop such policies. Antigua, Aruba, and Panama all have existing plastic bag bans in place. Interestingly, no plastic bags were documented among terrestrial litter in Aruba or Bonaire, only 1 was recorded in Panama and 4 were documented in Antigua. In contrast, prior to the plastic bag ban in Antigua and Barbuda in 2016, it was reported that plastic bags from supermarkets accounted for $90 \%$ of plastic litter found in the environment (UNEP, 2018a). In 2005, it was estimated that Aruba used 30 million single-use carry-out bags per year, most of which would have ended up in the environment or in landfill (UNEP, 2018a).

While plastic bags are the dominant item of focus for policy in the Caribbean, expanded polystyrene items are the second most common for national bans, one such country being Antigua. Only four whole foam plastic items were documented in terrestrial surveys in Antigua and Bonaire respectively, five in Panama, and 27 in Aruba. However, polystyrene fragments were found among the microplastic from surface water sampling, particularly in the waters around the San Blas archipelago, Panama suggesting that perhaps they are originating from elsewhere.

While this data may suggest that the enforcement of policies in the region is translating to certain items ending up in the environment less frequently, it is important to note that the Caribbean provides a case study on the importance of multinational efforts to prevent plastic pollution on a holistic level. As seen in the modelling and environmental data, there is potential for marine litter in the Caribbean to move through the prevailing ocean currents and to become highly fragmented over time before beaching. This means that policy in one location may not translate to less litter on their own coastline, and waste leakage can end up on other country's shorelines because of ocean currents. This further amplifies the importance of regional partnerships such as the Caribbean Waste Collective, the Trash Free Waters International Partnership, and the Caribbean Regional Action Plan for Marine Litter.

Throughout the Caribbean, marine litter and plastic pollution have increasingly become the focus of research, policy, and conservation efforts. It is clear that there are strategies in place to take action on this issue in the Caribbean, but also that the Caribbean is particularly vulnerable to the impacts of plastic pollution due to its high percentage of landfilling and open dumping, low percentage of recycling, finite and in some cases shrinking land area, physical location for oceanic transport of litter, its import of consumer goods and economic reliance on ocean-related activities such as fishing and tourism (Clayton et al., 2020; Diez et al., 2019; IDB, 2020). While nearly all Caribbean nations have taken steps towards implementing plastic policies, few have implemented comprehensive solid waste management plans, which would also serve a critical role to capture and contain waste and prevent it from entering the environment (Riquelme et al., 2016). There is no one solution for eliminating plastic pollution, interventions should be implemented in an integrated and complementary way. Research such as this can help to identify which interventions may be interlinked, resulting in the most significant impact.

\section{Conclusion}

It is clear that plastic pollution is an international challenge that demands interdisciplinary research and solutions. While this study provides a snapshot of data from a limited number of samples and countries in the Southern Caribbean region, collecting information in a holistic manner is critical to inform the most effective and integrated solutions to plastic pollution. The findings from this study illustrate that we can begin to better understand the multifaceted issue of plastic pollution if studies combine land-based data, ocean-based data, and physical modelling.

\section{CRediT authorship contribution statement}

Winnie Courtene-Jones: Conceptualization, Methodology, Formal analysis, Investigation, Data curation, Writing - original draft, Writing review \& editing, Supervision, Project administration. Taylor Maddalene: Methodology, Formal analysis, Investigation, Data curation, Visualization, Writing - original draft, Writing - review \& editing. Molly K. James: Methodology, Formal analysis, Investigation, Data curation, Visualization, Writing - original draft, Writing - review \& editing. Natalie S. Smith: Investigation, Writing - review \& editing. Kathryn Youngblood: Methodology, Formal analysis, Investigation, Data curation, Writing - original draft, Writing - review \& editing. Jenna R. Jambeck: Methodology, Supervision, Writing - review \& editing. Sally Earthrowl: Methodology, Supervision, Writing - review \& editing. Denise Delvalle-Borrero: Project administration, Writing - review \& editing. Emily Penn: Writing - review \& editing, Project administration, Funding acquisition. Richard C. Thompson: Supervision, Project administration, Writing - review \& editing, Funding acquisition.

\section{Declaration of competing interest}

The authors declare that they have no known competing financial interests or personal relationships that could have appeared to influence the work reported in this paper.

\section{Acknowledgements}

Great thanks are extended to Captain Anna Strang and the vessel crew, the shore team and guest crew on voyage legs 3-5 of eXXpedition 
Round the World. Thanks also to the Science Advisory Board and all sponsors who enabled this research, especially Travel Edge, TOMRA, SAP, Red Ensign Group, 11th Hour Racing and Slaughter and May. All necessary scientific permits for sampling within national waters were obtained from relevant authorities.

\section{Appendix A. Supplementary data}

Supplementary data to this article can be found online at https://doi. org/10.1016/j.scitotenv.2021.149098.

\section{References}

Acosta-Coley, I., Duran-Izquierdo, M., Rodriguez-Cavallo, E., Mercado-Camargo, J., Mendez-Cuadro, D., Olivero-Verbel, J., 2019a. Quantification of microplastics along the Caribbean coastline of Colombia: pollution profile and biological effects on Caenorhabditis elegans. Mar. Pollut. Bull. 146, 574-583.

Acosta-Coley, I., Mendez-Cuadro, D., Rodriguez-Cavallo, E., de la Rosa, J., Olivero-Verbel, J., 2019b. Trace elements in microplastics in Cartagena: a hotspot for plastic pollution at the Caribbean. Mar. Pollut. Bull. 139, 402-411.

Ambrose, K.K., Box, C., Boxall, J., Brooks, A., Eriksen, M., Fabres, J., Fylakis, G., Walker, T.R., 2019. Spatial trends and drivers of marine debris accumulation on shorelines in South Eleuthera, the Bahamas using citizen science. Mar. Pollut. Bull. 142, 145-154.

Andrady, A.L., 2011. Microplastics in the marine environment. Mar. Pollut. Bull. 62, 1596-1605.

Barboza, L.G.A., Dick Vethaak, A., Lavorante, B., Lundebye, A.K., Guilhermino, L., 2018. Marine microplastic debris: an emerging issue for food security, food safety and human health. Mar. Pollut. Bull. 133, 336-348.

Bashir, S., Goswami, S., 2016. Tourism induced challenges in municipal solid waste Management in Hill Towns: case of pahalgam. Procedia Environ. Sci. 35, 77-89.

Beaumont, N.J., Aanesen, M., Austen, M.C., Borger, T., Clark, J.R., Cole, M., Hooper, T., Lindeque, P.K., Pascoe, C., Wyles, K.J., 2019. Global ecological, social and economic impacts of marine plastic. Mar. Pollut. Bull. 142, 189-195.

Bosker, T., Guaita, L., Behrens, P., 2018. Microplastic pollution on Caribbean beaches in the Lesser Antilles. Mar. Pollut. Bull. 133, 442-447.

Botero, C.M., Zielinski, S., Pereira, C.I., Leon, J.A., Duenas, L.F., Puentes, V., 2020. The first report of deep-sea litter in the South-Western Caribbean Sea. Mar. Pollut. Bull. 157, 111327.

Brandon, J.A., Jones, W., Ohman, M.D., 2019. Multidecadal increase in plastic particles in coastal ocean sediments. Sci. Adv. 5, eaax0587.

Bucci, K., Tulio, M., Rochman, C.M., 2020. What is known and unknown about the effects of plastic pollution: a meta-analysis and systematic review. Ecol Appl. 30 (2), e02044. https://doi.org/10.1002/eap.2044.

Caribbean Tourism Organisation, 2020. Key Statistics from the Caribbean Toursm Organisation. Caribbean Tourism Organisation.

Clayton, C.A., Walker, T.R., Bezerra, J.C., Adam, I., 2020. Policy responses to reduce singleuse plastic marine pollution in the Caribbean. Mar. Pollut. Bull. 162, 111833.

Correa-Herrera, T., Barletta, M., Lima, A.R.A., Jimenez-Segura, L.F., Arango-Sanchez, L.B., 2017. Spatial distribution and seasonality of ichthyoplankton and anthropogenic debris in a river delta in the Caribbean Sea. J. Fish Biol. 90, 1356-1387.

Courtene-Jones, W., Quinn, B., Ewins, C., Gary, S.F., Narayanaswamy, B.E., 2020. Microplastic accumulation in deep-sea sediments from the rockall trough. Mar. Pollut. Bull. 154, 111092.

Crichton, E.M., Noël, M., Gies, E.A., Ross, P.S., 2017. A novel, density-independent and FTIRcompatible approach for the rapid extraction of microplastics from aquatic sediments. Anal. Methods 9, 1419-1428.

Davies, S., 2020. Disposable Plastic Ban Legislation Awaiting Approval. Info Bonaire.

Davranche, M., Lory, C., Juge, C.L., Blancho, F., Dia, A., Grassl, B., el Hadri, H., Pascal, P.-Y., Gigault, J., 2020. Nanoplastics on the coast exposed to the North Atlantic gyre: evidence and traceability. Nanolmpact 20.

de Scisciolo, T., Mijts, E.N., Becker, T., Eppinga, M.B., 2016. Beach debris on Aruba, southern Caribbean: attribution to local land-based and distal marine-based sources. Mar. Pollut. Bull. 106, 49-57.

Delandmeter, P., van Sebille, E., 2019. The parcels v2.0 lagrangian framework: new field interpolation schemes. Geosci. Model Dev. 12, 3571-3584.

Delvalle de Borrero, D., Fábrega Duque, J., Olmos, J., Garcés-Ordóñez, O., Amaral, S.S.G.D., Vezzone, M., De Sá Felizardo, J.P., Meigikos Dos Anjos, R., 2020. Distribution of plastic debris in the pacific and Caribbean beaches of Panama. Air Soil Water Res. 13.

Dibke, C., Fischer, M., Scholz-Bottcher, B.M., 2021. Microplastic mass concentrations and distribution in German bight waters by pyrolysis-gas chromatography-mass spectrometry/thermochemolysis reveal potential impact of marine coatings: do ships leave skid marks? Environ. Sci. Technol. 55, 2285-2295.

Diez, S.M., Patil, P.G., Morton, J., Rodriguez, D.J., Vanzella, A., Robin, D.V., Maes, T., Corbin, C., 2019. Marine Pollution in the Caribbean: Not a Minute to Waste. World Bank Group, Washington, D.C.

Dinno, A., 2017. dunn.test: Dunn\&apos;s Test of Multiple Comparisons Using Rank Sums.

Galloway, T.S., Cole, M., Lewis, C., 2017. Interactions of microplastic debris throughout the marine ecosystem. Nat. Ecol. Evol. 1, 116.

Garces-Ordonez, O., Espinosa Diaz, L.F., Pereira Cardoso, R., Costa Muniz, M., 2020a. The impact of tourism on marine litter pollution on Santa Marta beaches, Colombian Caribbean. Mar. Pollut. Bull. 160, 111558.
Garces-Ordonez, O., Espinosa, L.F., Cardoso, R.P., Issa Cardozo, B.B., Meigikos Dos Anjos, R. 2020b. Plastic litter pollution along sandy beaches in the Caribbean and Pacific coast of Colombia. Environ. Pollut. 267, 115495.

Geyer, R., Jambeck, J.R., Law, K.L., 2017. Production, use, and fate of all plastics ever made. Sci. Adv. 3, e1700782.

Hardesty, B.D., Harari, J., Isobe, A., Lebreton, L., Maximenko, N., Potemra, J., van Sebille, E., Vethaak, A.D., Wilcox, C., 2017. Using numerical model simulations to improve the understanding of micro-plastic distribution and pathways in the marine environment. Front. Mar. Sci. 4.

Hidalgo-Ruz, V., Gutow, L., Thompson, R.C., Thiel, M., 2012. Microplastics in the marine environment: a review of the methods used for identification and quantification. Environ. Sci. Technol. 46, 3060-3075.

IDB, 2020. Plastic Waste Management and Leakage in Latin America and the Caribbean.

Jones-Williams, K., Galloway, T., Cole, M., Stowasser, G., Waluda, C., Manno, C., 2020. Close encounters - microplastic availability to pelagic amphipods in sub-antarctic and antarctic surface waters. Environ. Int. 140, 105792.

Kaandorp, M.L.A., Dijkstra, H.A., van Sebille, E., 2020. Closing the Mediterranean marine floating plastic mass budget: inverse modeling of sources and sinks. Environ. Sci. Technol. 54, 11980-11989.

Karasik, R., Vegh, T., Diana, Z., Bering, J., Caldas, J., A, P., Rittschof, D., Virdin, J., 2020. 20 Years of Government Responses to the Global Plastic Pollution Problem.

Karin, T., 2020. Global Land Mask.

Kaza, S., Yao, L., Bhada-Tata, P., van Woerden, F., 2018. What a Waste 2.0: A Global Snapshot of Solid Waste Management to 2050. World Bank, Washington, DC.

Kikaki, A., Karantzalos, K., Power, C.A., Raitsos, D.E., 2020. Remotely sensing the source and transport of marine plastic debris in Bay Islands of Honduras (Caribbean Sea). Remote Sens. 12.

Kukulka, T., Proskurowski, G., Morét-Ferguson, S., Meyer, D.W., Law, K.L., 2012. The effect of wind mixing on the vertical distribution of buoyant plastic debris. Geophys. Res. Lett. 39, n/a-n/a.

Kutralam-Muniasamy, G., Perez-Guevara, F., Elizalde-Martinez, I., Shruti, V.C., 2020. Review of current trends, advances and analytical challenges for microplastics contamination in Latin America. Environ. Pollut. 267, 115463.

Law, K.L., Moret-Ferguson, S.E., Goodwin, D.S., Zettler, E.R., Deforce, E., Kukulka, T., Proskurowski, G., 2014. Distribution of surface plastic debris in the eastern Pacific Ocean from an 11-year data set. Environ. Sci. Technol. 48, 4732-4738.

Lebreton, L., Andrady, A., 2019. Future scenarios of global plastic waste generation and disposal. Palgrave Commun. 5.

Lebreton, L.C., Borrero, J.C., 2013. Modeling the transport and accumulation floating debris generated by the 11 March 2011 Tohoku tsunami. Mar. Pollut. Bull. 66, 53-58.

Luken, K., 2017. SIDS approaches to waste management and the circular economy. Caribbean Waste Management Conference. UNEP, Kingston, Jamaica, p. 61.

Mateu-Sbert, J., Ricci-Cabello, I., Villalonga-Olives, E., Cabeza-Irigoyen, E., 2013. The impact of tourism on municipal solid waste generation: the case of Menorca Island (Spain). Waste Manag. 33, 2589-2593.

Mazariegos-Ortiz, C., De Los Angeles Rosales, M., Carrillo-Ovalle, L., Cardoso, R.P., Muniz M.C., Dos Anjos, R.M., 2020. First evidence of microplastic pollution in the El Quetzalito sand beach of the Guatemalan Caribbean. Mar. Pollut. Bull. 156, 111220.

Muller-Karanassos, C., Turner, A., Arundel, W., Vance, T., Lindeque, P.K., Cole, M., 2019. Antifouling paint particles in intertidal estuarine sediments from Southwest England and their ingestion by the harbour ragworm, Hediste diversicolor. Environ. Pollut. 249, 163-170.

Myers, N., Mittermeier, R.A., Mittermeier, C.G., da Fonseca, G.A.B., Kent, J., 2000. Biodiversity hotspots for conservation priorities. Nature 403, 853-858.

Oksanen, J., Blanchet, F.G., Friendly, M., Kindt, R., Legendre, P., Mcglinn, D., Minchin, R., P. R, O'Hara, R.B., Simpson, G.L., Solymos, P., Stevens, M.H.H., Szoecs, E., Wagner, H., 2019. vegan: Community Ecology Package.

Ostle, C., Thompson, R.C., Broughton, D., Gregory, L., Wootton, M., Johns, D.G., 2019. The rise in ocean plastics evidenced from a 60-year time series. Nat. Commun. 10, 1622.

Phillips, W., 2014. Towards diversification of the tourism sector. A recreational demand study of yachting and marina services in the Caribbean. Studies and perspectives series-The Caribbean. Economic Commission for Lation America and the Caribbean.

Phillips, W., Thorne, E., 2013. Municipal solid waste management in the Caribbean. ECLAC - Studies and Perspectives Series - The Caribbean.

PepsiCo, 2019. PepsiCo Latin America Doubles Down on Its Commitment to Inclusive Recycling by Launching "Recycling with Purpose", a Program That Will Promote a Circular Economy. PepsiCo: PepsiCo.

R Core Team, 2019. R: A Language and Environment for Statistical Computing. R Foundation for Statistical Computing, Vienna, Austria.

Rangel-Buitrago, N., Williams, A., Anfuso, G., 2018. Killing the goose with the golden eggs: litter effects on scenic quality of the Caribbean coast of Colombia. Mar. Pollut. Bull. 127, 22-38.

Rangel-Buitrago, N., Gracia, C.A., Velez-Mendoza, A., Carvajal-Florián, A., Mojica-Martinez, L., Neal, W.J., 2019. Where did this refuse come from? Marine anthropogenic litter on a remote island of the Colombian Caribbean sea. Mar. Poll. Bull. 149.

Rangel-Buitrago, N., Arroyo-Olarte, H., Trilleras, J., Arana, V.A., Mantilla-Barbosa, E., Gracia, C.A., Mendoza, A.V., Neal, W.J., Williams, A.T., Micallef, A., 2021. Microplastics pollution on colombian Central Caribbean beaches. Mar. Pollut. Bull. 170, 112685.

Reisser, J., Slat, B., Noble, K., du Plessis, K., Epp, M., Proietti, M., de Sonneville, J., Becker, T., Pattiaratchi, C., 2015. The vertical distribution of buoyant plastics at sea: an observational study in the North Atlantic gyre. Biogeosciences 12, 1249-1256.

República De Panamá, 2020. In: Panamá, República De (Ed.), Que regula la reducción y el reemplazo progresivo de los plásticos de un solo uso. Gaceta Oficial Digital.

Riquelme, R., Méndez, P., Smith, I., 2016. Solid Waste Management in the Caribbean Proceedings From the Caribbean Solid Waste Conference. 
Rockström, J., Steffen, W., Noone, K., Persson, Å., Chapin, F.S., Lambin, E., 2009. Planetary boundaries: exploring the safe operating space for humanity. Nature 14, 472-475.

Saito, O., 2013. Resource use and waste generation by the tourism industry on the Big Island of Hawaii. J. Ind. Ecol. 17, 578-589.

Schonlau, C., Karlsson, T.M., Rotander, A., Nilsson, H., Engwall, M., van Bavel, B., Karrman, A., 2020. Microplastics in sea-surface waters surrounding Sweden sampled by manta trawl and in-situ pump. Mar. Pollut. Bull. 153, 111019.

Sutherland, W.J., Clout, M., Cote, I.M., Daszak, P., Depledge, M.H., Fellman, L., Fleishman, E., Garthwaite, R., Gibbons, D.W., de Lurio, J., Impey, A.J., Lickorish, F., Lindenmayer, D., Madgwick, J., Margerison, C., Maynard, T., Peck, L.S., Pretty, J., Prior, S., Redford, K.H., Scharlemann, J.P., Spalding, M., Watkinson, A.R., 2010. A horizon scan of global conservation issues for 2010. Trends Ecol. Evol. 25, 1-7.

The World Bank, 2019. In: The World Bank (Ed.), Population, Total- Latin America and Caribbean.

Turner, A., 2010. Marine pollution from antifouling paint particles. Mar. Pollut. Bull. 60, $159-171$.

UNEP, 2014. Regional Action Plan on Litter Management (RAPMaLi) for the Wider Caribbean Region 2014.

Unep, 2018a. Report in the status of styrofoam and plastic bag bans in the wider Caribbean region. Fourth Meeting of the Scientific, Technical and Advisory Committee (STAC) to the Protocol concerning Pollution from Land based Sources and Activities in the Wider Caribbean.
Unep, 2018b. Waste Management Outlook for Latin America and the Caribbean. United Nations Environment Programme.

Van Sebille, E., Aliani, S., Law, K.L., Maximenko, N., Alsina, J.M., Bagaev, A., Bergmann, M., Chapron, B., Chubarenko, I., Cózar, A., Delandmeter, P., EGGER, P., Fox-Kemper, B. Garaba, S.P., Goddijn-Murphy, L., Hardesty, B.D., Hoffman, M.J., Isobe, A., Jongedijk, C.E., Egger, M., Kaandorp, M.L.A., Khatmullina, L., Koelmans, A.A., Kukulka, T., Laufkötter, C., Lebreton, L., Lobelle, D., Maes, C., Martinez-Vicente, V., Morales Maqueda, M.A., Poulain-Zarcos, M., Rodríguez, E., Ryan, P.G., Shanks, A.L., Shim, W.J. Suaria, G., Thiel, M., Van Den Bremer, T.S., Wichmann, D., 2020. The physical oceanography of the transport of floating marine debris. Environ. Res. Lett. 15.

Wickham, H., François, R., Henry, L., Müller, K., 2020. dplyr: A Grammar of Data Manipulation.: R Package Version 1.0.2

Wilkinson, C., Salvat, B., 2012. Coastal resource degradation in the tropics: does the tragedy of the commons apply for coral reefs, mangrove forests and seagrass beds. Mar Pollut. Bull. 64, 1096-1105.

World Travel and Tourism Council, 2020. Tavel and tourism economic impact 2019 world https://wttc.org/Research/Economic-Impact.

Wyles, K.J., Pahl, S., Thomas, K., Thompson, R.C., 2016. Factors that can undermine the psychological benefits of coastal environments: exploring the effect of tidal state, presence, and type of litter. Environ. Behav. 48, 1095-1126.

Zappino, W., 2005. Caribbean Tourism and Development: An Overview. 